\title{
Synergistic interaction of Helichrysum pedunculatum leaf extracts with antibiotics against wound infection associated bacteria
}

\author{
AIYEGORO OLAYINKA A ${ }^{1}$, AFOLAYAN ANTHONY J ${ }^{2}$, and OKOH ANTHONY I ${ }^{1, *}$ \\ ${ }^{1}$ Applied and Environmental Microbiology Research Group, Department of Biochemistry and Microbiology, \\ University of Fort Hare, Alice 5700, South Africa \\ ${ }^{2}$ Phytomedicine Research Group, Department of Botany, Plant Science Building, University of Fort Hare, \\ Alice 5700, South Africa
}

\begin{abstract}
The effect of combinations of the crude methanolic extract of the leaves of Helichrysum pedunculatum and eight first-line antibiotics were investigated by time kill assays against a panel of bacterial strains that have been implicated in wound infections. The plant extract showed appreciable antibacterial activities against the test bacteria with zones of inhibition ranging between 18 and $27 \mathrm{~mm}$, and minimum inhibitory concentrations (MICs) varying between 0.1 and $5.0 \mathrm{mg} / \mathrm{ml}$. The MICs of the test antibiotics range between 0.001 and 0.412 $\mathrm{mg} / \mathrm{ml}$, and combination of the plant extract and the antibiotics resulted in reduction of bacterial counts by between 0 and $6.63 \log _{10} \mathrm{cfu} / \mathrm{ml}$. At $1 / 2$ MIC, $56.81 \%$ synergy; $43.19 \%$ indifference and no antagonism were observed, and at MIC levels, 55.68\% synergy; $44.32 \%$ indifference and no antagonism were observed when the extracts were combined with eight different antibiotics. In all, $60 \%$ of the interactions were synergistic. All combination regimes on Staphylococcus aureus ATCC 6538 yielded no synergy, neither was antagonism detected in any of the assays. We propose that extracts of the leaves of Helichrysum pedunculatum could be of relevance in combination therapy and as a source of resistance modifying principles that could be useful as treatment options for persistent wound infections.
\end{abstract}

Key terms: Helichrysum pedunculatum, time kill assay, synergism.

\section{INTRODUCTION}

The optimism of the early period of antimicrobial discovery has been tempered by the emergence of bacteria strains with resistance to these antibiotic therapies. Today, clinically important bacteria are characterized not only by single drug resistance, but also by multiple antibiotic resistances - the legacy of past decades of antimicrobial use and misuse (Levy, 2002). Drug resistance presents an ever increasing global health threat that involves all major microbial pathogens and antimicrobial drugs (Stuart and Bonnie, 2005). Antimicrobial resistance is not new, but the number of resistant organisms, the geographic locations affected by drug resistance, and the breadth of resistance in single organisms are unprecedented and mounting (Levy, 2002). Antibiotic resistance has increased substantially in recent years and is posing an ever-increasing therapeutic problem (Guillemot, 1999; Austin et al., 1999).

Plants are of great medicinal importance to the health of man. The curative potentials of these plants are locked-up and embedded in some chemical components that effect physiological responses in man (Edeoga et al., 2005). Many of these medicinal plants are used as spices and food plants. They are also sometimes added to foods meant for pregnant and nursing mothers for medicinal purposes (Okwu, 1999, 2001). Historically,

\footnotetext{
* Correspondence to: Professor AI Okoh, Applied and Environmental Microbiology Research Group (AEMREG), Department of Biochemistry and Microbiology, University of Fort Hare, Alice 5700, South Africa. E-mail: aokoh@ufh.ac.za; Tel: +27406022365 (office); +27822249760 (cell); I-Fax: 0866286824.
} 
plants have provided a source of inspiration for novel drug compounds, as plant-derived medicines have made large contributions to human health and well-being. Their role is two-fold in the development of new drugs: (i) they may become the base for the development of a medicine, a natural blue print for the development of new drugs, or; (ii) they may be used for the treatment of diseases (Iwu, 1993).

The primary benefits of using plantderived medicines are that they are safer than synthetic alternatives, offering profound therapeutic benefits and more affordable treatment (Robbers et al., 1996). They are effective with minimal or no side effects in the treatment of infectious diseases, while simultaneously mitigating many of the side effects that are often associated with synthetic drugs. Many plants have tropism to specific organs or systems in the body (Robbers et al., 1996). Phytomedicine usually have multiple effects on the body and their actions often act beyond the symptomatic treatment of diseases as shown in Hydrastis canadensis (Murray, 1995). Apart from antimicrobial activities of this plant, it also increases blood supply to the spleen and thus promoting optimal activity of the tissue to release mediating compounds (Murray, 1995).

As certain antibiotic treatments lead to the development of multiresistant organisms, it is now standard clinical practice to use a combination of two or more antibiotics with different mechanisms of action in an attempt to prevent the development of antibiotic resistance and improve the outcome of therapy (Beringer, 1999). Combination therapy can be used to expand the antimicrobial spectrum, to prevent the emergence of resistant mutants, to minimize toxicity, and to obtain synergistic antimicrobial activity. Synergism is a positive interaction created when two agents combined and exert an inhibitory effect (on the targeted organisms) that is greater than the sum of their individual effects.

Reports have shown that in addition to the production of intrinsic antimicrobial compounds, plants also produce multi-drug resistance (MDR) inhibitors that enhance the activity of antimicrobial compounds
(Ahmad and Aqil, 2007; Sibanda and Okoh, 2008). The screening of crude plant extracts for synergistic interaction with antibiotics is expected to provide leads for the isolation of MDR inhibitors. The use of Catha edulis extracts at subinhibitory levels has been reported to reduce the minimum inhibitory concentration (MIC) values of tetracycline and penicillin $G$ against resistant oral pathogens, Streptococcus oralis, Streptococcus sanguis and Fusobacterium nucleatum (Al- hebshi et al., 2006). A number of compounds with an in vitro activity of reducing the MICs of antibiotics against resistant organisms have also been isolated from plants. Polyphenols (epicatechin gallate and catechin gallate) have been reported to reverse beta-lactam resistance in Methicillin Resistant Staphylococcus aureus (MRSA) (Stapleton et al., 2004). Diterpenes, triterpenes, alkyl gallates, flavones and pyridines have also been reported to have resistance modulating abilities on various antibiotics against resistant strains of Staphylococcus aureus (Marquez et al., 2005; Smith et al., 2007).

The genus Helichrysum a perennial herb belongs to the tribe Inuleae in the Asteraceae family and is known for its aromatic and therapeutic properties. It is a large family of about 500 species, with 245 species indigenous to South Africa (Mathekga et al., 2000).

Helichrysum pendunculatum Hilliard and Burtt (Asteraceae) are widely distributed within the range of the borders of Southern Lesotho to the Eastern Cape Province of South Africa (Meyer and Dilika, 1996). The people of the Eastern Cape Province of South Africa commonly use the plant to dress wounds acquired after circumcision rites. In addition, Helichrysum species have been used to treat coughs, colds, fever, infections, headache, menstrual pain, and as a wound dressing in areas as far apart as Europe, Egypt, North America, China, Australia and South Africa (Hutchings, 1996; Bhat and Jacobs, 1995), and are included in many pharmacopoeias. Many cultures, including African, European, Eastern and North American, use Helichrysums in food and medicine. In Europe, the Helichrysum ranks as one of the 
most ancient and valuable healing substances. It is said to be more antiinflammatory than German Chamomile; have more tissue regenerating power than Lavender and more cicatrisant (the formation of scar tissue) than Frankincense [http: //herbalafrica.co.za/Helichrysum.htm]. Furthermore, oil of Helichrysum has been found by European researchers to generate tissue, reduce tissue pain, helps improve skin conditions, circulatory function, prevents phlebitis, helps regulate cholesterol, stimulates liver cell function and reduces scarring and discoloration. It is an anticoagulant, anticatarrhal, expectorant, and antispasmodic (Czinner et al., 2000). In Africa, Helichrysums are often used for food - the leaves are cooked and eaten. Medicinally, the roots, leaves, stems and flowers are used as traditional medicine for chest complaints, colic in children, coughs, colds, internal sores, fever, headaches, and for dressing wounds (Mathekga et al., 2000).

$H$. pedunculatum leaf extracts have previously been studied for bioactivity (Aiyegoro et al., 2008; Grierson and Afolayan, 1999), however, the interactions between the extracts of this plant and antibiotics have not been documented, especially with regards to its potential as a source of resistance modifying compounds. In this paper, we investigated the inhibitory activity of crude methanol extract of $H$. pedunculatum leaves against bacterial pathogens that are implicated in wound infections. The effect of combinations of the extract and some antibiotics on their resistance modifying potencies was also studied in our effort to explore for new bioactive molecules of pharmaceutical importance in the management of wound infections.

\section{MATERIALS AND METHODS}

\section{Plant material}

$H$. pedunculatum leaves were collected from the vicinity of the Research Farm of the University of Fort Hare, Alice, Eastern Cape Province of South Africa, in the month of September 2007. The plant materials were compared to the voucher specimen at the Griffin's Herbarium of the Plant Science Building of the University of Fort Hare in Alice. The leaves were picked and washed with water to remove all unwanted materials and air-dried, pulverized in a mill (Christy Lab Mill, Christy and Norris Ltd; Process Engineers, Chelmsford, England) and stored in a sterile air-tight container for further use.

\section{Plant extract preparation}

The extract of the leaves was prepared in accordance to the description of Basri and Fan (2005). One hundred and fifty grams of powdered leaves was steeped in $500 \mathrm{ml}$ of methanol, for $24 \mathrm{~h}$ with shaking (Stuart Scientific Orbital Shaker, UK). The resultant extracts were centrifuged at 3000 $\mathrm{rpm}$ for $5 \mathrm{~min}$ at $4{ }^{\circ} \mathrm{C}$. The supernatant was then filtered through a Whatman No.1 filter paper while the residue was used for a second extraction with $300 \mathrm{ml}$ of methanol. After the second extraction, the filtrates were concentrated under reduced pressure using a rotary evaporator (Laborota 4000efficient, Heldolph, Germany) at $50{ }^{\circ} \mathrm{C}$. The crude extract collected was allowed to dry at room temperature to a constant weight of $11.2 \mathrm{~g}(7.47 \%)$.

\section{Preparation of bacterial inocula}

Bacterial isolates used in this study included reference strains obtained from the South African Bureau of Standards (SABS); Streptococcus faecalis (ATCC 29212), Staphylococcus aureus (ATCC 6538), Bacillus pumilus (ATCC 14884), Klebsiella pneumoniae (ATCC 10031) and Proteus vulgaris (CSIR 0030). The environmental strains include Micrococcus kristinae, Micrococcus luteus, Proteus vulgaris, Klebsiella pneumonia, Bacillus subtilis, Staphylococcus epidermidis, which were obtained from the Applied and Environmental Microbiology Research Group (AEMREG), Department of Biochemistry and Microbiology, University of Fort Hare, Alice, South Africa.

The inocula of the test organisms were prepared using the colony suspension 
method (EUCAST, 2000). Colonies picked from $24 \mathrm{~h}$ old cultures grown on nutrient agar were used to make suspensions of the test organisms in saline solution to give an optical density of approximately 0.1 at 600 $\mathrm{nm}$. The suspension was then diluted 1: 100 by transfer of $0.1 \mathrm{ml}$ of the bacterial suspension to $9.9 \mathrm{ml}$ of sterile nutrient broth before use.

\section{Antibiotics used in this study}

The following antibiotics were used in this study: Penicillin G sodium (Duchefa), Amoxicillin (Duchefa), Chloramphenicol (Duchefa), Oxytetracycline (Duchefa), Ampicilin sodium salt (Calbiochem), Tetracycline hydrochloride (Duchefa), Erythromycin (Duchefa) and Ciprofloxacin (Fluka).

\section{Sensitivity testing of the crude plant extract}

The sensitivity testing of the crude extract of the plant was determined using the agar-well diffusion method as described by Irobi et al., (1996), with modifications. The bacterial isolates were first grown in nutrient broth for $24 \mathrm{~h}$ to prepare bacterial suspension as described above. The bacterial suspension $(0.1 \mathrm{ml})$ was inoculated into molten MuellerHinton agar medium at $50{ }^{\circ} \mathrm{C}$ and then poured into a sterile Petri dish, the plate was allowed to set and wells were then bored into the agar medium using a sterile $6 \mathrm{~mm}$ cork borer. The wells were later filled up with about $0.2 \mathrm{ml}$ of the extract at a concentration of $5 \mathrm{mg} / \mathrm{ml}$ taking care to prevent spillage onto the surface of the agar medium. The plates were allowed to stand on the laboratory bench for $1 \mathrm{~h}$ to allow proper diffusion of the extract into the medium and then incubated at $37{ }^{\circ} \mathrm{C}$ for $24 \mathrm{~h}$, after which they were observed for zones of inhibition. Tetracycline and ampicilin at concentration of $0.1 \mathrm{mg} / \mathrm{ml}$ and $10 \mu \mathrm{g} / \mathrm{ml}$, respectively, were used as controls.

\section{Determination of the minimum inhibitory concentrations (MICs)}

The minimum inhibitory concentrations (MICs) of the antibiotics and plant extracts were determined using the standard method of the European Committee for Antimicrobial Susceptibility Testing (EUCAST, 2000). Dilutions of the antibiotics, ranging from $0.001-0.824 \mathrm{mg} /$ $\mathrm{ml}$ in nutrient agar (Biolab), were prepared by incorporating the antibiotic stock solution into molten agar at $50{ }^{\circ} \mathrm{C}$. Dilutions of the extract ranging from 0.05 $20 \mathrm{mg} / \mathrm{ml}$ were also prepared and incorporated into molten nutrient agar (Biolab) at $50{ }^{\circ} \mathrm{C}$ and poured into sterile plates. The plates were allowed to set and then inoculated with standardized inocula of the test bacteria by streaking. Plates were incubated at $37{ }^{\circ} \mathrm{C}$ for $24 \mathrm{~h}$ under aerobic conditions. The MIC was defined as the lowest concentration of the antibiotic or extracts that completely inhibited visible growth of the test organism.

\section{Antibiotic-extract combination experiment} (The time-kill method)

The effect of combinations of the methanolic extract of $H$. pendunculatum leaves and selected antibiotics was evaluated using the time-kill assay method in accordance with the descriptions of White et al. (1996) and Pankey et al. (2005). The extracts and antibiotics were incorporated into $50 \mathrm{ml}$ of nutrient broth at $0.5 \times \mathrm{MIC}$ and $1 \times$ MIC, respectively. Controls consisting of nutrient broth incorporated with the extract and the respective antibiotic without the test organism at the test concentrations were included in each experiment. The test and control flasks were inoculated with each test organism to a final inoculum density of approximately $10^{5} \mathrm{cfu} / \mathrm{ml}$. Immediately after inoculation, aliquots $(100 \mu \mathrm{l})$ of the negative control flasks were taken, serially diluted in sterile physiological saline and plated on nutrient agar in order to determine the zero hour counts. The test flasks were incubated at $37^{\circ} \mathrm{C}$ with shaking at $120 \mathrm{rpm}$. After $24 \mathrm{~h}$ of incubation, samples were taken from control and each test flask. The samples from the test flask were transferred to a recovery medium containing $3 \%$ to neutralize the effects of the crude extract carry-overs from the test 
suspensions. Both samples from the recovery medium and the control flasks were then serially diluted in sterile physiological saline. This was later plated on nutrient agar in duplicates. For a better visual observation of the colonies on the agar, $1 \mathrm{ml}$ of $0.5 \%$ aqueous solution of 2,3,5 triphenol tetrazolium chloride (Neugebauer and Gilliland, 2005) was added to $100 \mathrm{ml}$ of the molten agar before plating. The plates were incubated at $37{ }^{\circ} \mathrm{C}$ for $24 \mathrm{~h}$ under aerobic conditions. After incubation, the numbers of colonies were enumerated and the mean counts $(\mathrm{cfu} / \mathrm{ml})$ for each test and controls were determined and expressed as $\log _{10}$. The interactions were considered synergistic if there was a decrease of $\geq 2 \log _{10} \mathrm{cfu} / \mathrm{ml}$ in colony counts after $24 \mathrm{~h}$ by the combination compared to the most active single agent (Pankey et al., 2005). Additivity or indifference was described as a $<2 \log _{10}$ $\mathrm{cfu} / \mathrm{ml}$ change in the average viable counts after $24 \mathrm{~h}$ for the combination, in comparison to the most active single drug. Antagonism was defined as a $\geq 2 \log _{10} \mathrm{cfu} /$ $\mathrm{ml}$ increase in colony counts after $24 \mathrm{~h}$ by the combination compared to that by the most active single agent alone (Pankey et al., 2005; Lee et al., 2006).

\section{RESULTS}

The results of these experiments revealed that crude methanolic extract of Helichrysum pedunculatum leaves exhibited antibacterial activities against all of the test bacterial isolates comprising both Gramnegative and Gram-positive bacteria at a screening concentration of $5 \mathrm{mg} / \mathrm{ml}$. Part of this result has been published in our article (Aiyegoro et al., 2008) (Table i). Zones of inhibition ranged from 20 to $27 \mathrm{~mm}$ for the reference organisms, and from $18 \mathrm{~mm}$ to 25 $\mathrm{mm}$ for the environmental strains. The lowest zone of inhibition exhibited was 18 mm against environmental strain of Bacillus subtilis, while the highest zone of inhibition was $27 \mathrm{~mm}$ against Klebsiella pneumoniae (ATCC 10031) by the crude extract. The antibiotics, ampicilin and tetracycline yield zones of inhibition of 13$30 \mathrm{~mm}$ and 10-28 $\mathrm{mm}$ respectively.

The minimum inhibitory concentrations (MICs) of the crude extract of $H$. pedunculatum leaves, along with that of eight frontline antibiotics (ampicilin; tetracycline; penicillin G; erythromycin; amoxicillin; ciprofloxacin; chloramphenicol; oxytetracycline) used in the combination experiment, were also determined (Table ii).

TABLE I

Sensitivity patterns of zones of inhibition exhibited by $H$. pedunculatum crude methanol leaf extract against the bacterial isolates

\begin{tabular}{|c|c|c|c|c|}
\hline \multirow[t]{2}{*}{ Bacterial isolates } & \multicolumn{3}{|c|}{ Zones of inhibition $(\mathrm{mm})^{*}$} & \multirow[b]{2}{*}{$\begin{array}{l}\text { Ampicilin } \\
(10 \mu \mathrm{g} / \mathrm{ml})\end{array}$} \\
\hline & $\begin{array}{c}\text { Control } \\
(5 \% \text { Methanol })\end{array}$ & $\begin{array}{l}\text { H. pedunculatum } \\
\text { extract }(5 \mathrm{mg} / \mathrm{ml})\end{array}$ & $\begin{array}{l}\text { Tetracycline } \\
(0.1 \mathrm{mg} / \mathrm{ml})\end{array}$ & \\
\hline Staphylococcus aureus ATCC 6538 & $0.0 \pm 0.0^{\mathrm{b}}$ & $20 \pm 0.6^{\mathrm{a}}$ & $20 \pm 1.0^{\mathrm{a}}$ & $24 \pm 0.3^{\mathrm{a}}$ \\
\hline Streptococcus faecalis ATCC 29212 & $0.0 \pm 0.0^{\mathrm{c}}$ & $23 \pm 0.3^{\mathrm{a}}$ & $19 \pm 0.4^{\mathrm{b}}$ & $17 \pm 0.4^{\mathrm{b}}$ \\
\hline Bacillus pumilus ATCC 14884 & $0.0 \pm 0.0^{\mathrm{c}}$ & $20 \pm 0.3^{b}$ & $28 \pm 0.0^{\mathrm{a}}$ & $23 \pm 1.6^{\mathrm{b}}$ \\
\hline Klebsiella pneumoniae ATCC 10031 & $0.0 \pm 0.0^{\mathrm{c}}$ & $27 \pm 0.7^{\mathrm{a}}$ & $23 \pm 1.3^{\mathrm{a}}$ & $14 \pm 0.0^{\mathrm{b}}$ \\
\hline Proteus vulgaris CSIR 0030 & $0.0 \pm 0.0^{\mathrm{c}}$ & $20 \pm 0.2^{\mathrm{a}}$ & $14 \pm 1.7^{b}$ & $15 \pm 1.9^{b}$ \\
\hline Klebsiella pneumoniae ${ }^{\S}$ & $0.0 \pm 0.0^{\mathrm{c}}$ & $25 \pm 1.1^{\mathrm{a}}$ & $15 \pm 0.9^{b}$ & $13 \pm 1.0^{\mathrm{b}}$ \\
\hline Bacillus subtilis ${ }^{\S}$ & $0.0 \pm 0.0^{\mathrm{d}}$ & $18 \pm 1.6^{\mathrm{c}}$ & $22 \pm 0.6^{b}$ & $30 \pm 0.9^{\mathrm{a}}$ \\
\hline Staphylococcus epidermidis ${ }^{\S}$ & $0.0 \pm 0.0^{\mathrm{d}}$ & $20 \pm 0.5^{\mathrm{a}}$ & $10 \pm 0.6^{\mathrm{c}}$ & $17 \pm 0.2^{b}$ \\
\hline Proteus vulgaris ${ }^{\S}$ & $0.0 \pm 0.0^{\mathrm{c}}$ & $25 \pm 1.6^{\mathrm{a}}$ & $22 \pm 0.0^{\mathrm{b}}$ & $19 \pm 0.0^{\mathrm{b}}$ \\
\hline Micrococcus kristinae $\S$ & $0.0 \pm 0.0^{\mathrm{b}}$ & $20 \pm 0.7^{a}$ & $18 \pm 0.6^{a}$ & $18 \pm 2.0^{\mathrm{a}}$ \\
\hline Micrococcus luteus $\S$ & $0.0 \pm 0.0^{\mathrm{c}}$ & $25 \pm 0.2^{\mathrm{a}}$ & $17 \pm 1.2^{\mathrm{b}}$ & $13 \pm 1.6^{\mathrm{b}}$ \\
\hline
\end{tabular}

\footnotetext{
$\S$ Environmental strain; * Mean of three replicates; Values followed by the same letter along the rows are not
} significantly different $(\mathrm{P}>0.05)$ 
The MICs of the crude extract and the antibiotics varied between $1 \mu \mathrm{g} / \mathrm{ml}$ and 5.0 $\mathrm{mg} / \mathrm{ml}$. Specifically, the MICs ranged from 0.1 to $5.0 \mathrm{mg} / \mathrm{ml}$ for the extract; 0.001 to $0.032 \mathrm{mg} / \mathrm{ml}$ for tetracycline; 0.001 to 0.412 $\mathrm{mg} / \mathrm{ml}$ for penicillin $\mathrm{G}$, erythromycin and amoxycillin; 0.001 to $0.004 \mathrm{mg} / \mathrm{ml}$ for ciprofloxacin and ampicilin; 0.004 to 0.256 $\mathrm{mg} / \mathrm{ml}$ for chloramphenicol; 0.002 to $0.032 \mathrm{mg} / \mathrm{ml}$ for oxytetracycline. The lowest MIC value exhibited by the extract was against Micrococcus kristinae $(0.1 \mathrm{mg} / \mathrm{ml})$ while the highest MIC observed was $5.0 \mathrm{mg} /$ $\mathrm{ml}$ against Staphylococcus aureus (ATCC 6538), Bacillus pumilus (ATCC 14884), Proteus vulgaris (CSIR 0030) and Klebsiella pneumoniae (Table ii).

The time kill effect of combinations of the methanol extract of $H$. pedunculatum leaves and antibiotics is shown in Table iii. The extract showed ability to improve the bactericidal effect of the antibiotics on both Gram-positive and Gram-negative microorganisms. The highest bactericidal activity exemplified by a $6.63 \pm 0.5 \log _{10}$ reduction in cell density was observed against Staphylococcus epidermidis (environmental strain) when the extract and Penicillin $G$ are combined at $1 / 2 \mathrm{MIC}$ values. At $1 / 2 \mathrm{MIC}$ level, $56.81 \%$ synergy; $43.19 \%$ indifference and no antagonism were observed; and at MIC level,
$55.68 \%$ synergy; $44.32 \%$ and no antagonism were observed.

Synergy rate of $59.1 \%$ (Extract + Tetracycline; Extract + Amoxycillin), $54.6 \%$ (Extract + Penicillin G; Extract + Chloramphenicol), $63.6 \%$ (Extract + Ciprofloxacin; Extract + Oxytetracycline), $68.2 \%$ (Extract + Erythromycin) and $27.3 \%$ (Extract + Ampicilin) were observed on all the test isolates at both $1 / 2 \mathrm{MIC}$ and MIC values. Overall, synergistic response constituted about $60 \%$ of all manner of combinations of extract and antibiotics against all test organisms. All manner of combination against Staphylococcus aureus (ATCC 6538) yielded no synergy (100\% indifference) and antagonism was not detected among the 176 tests carried out.

\section{DISCUSSION}

The organisms used in this study were reference and environmental strains of pathogenic organisms often posing problems of drug resistance in clinical settings. In order to assess the effects of combinations between the extracts of the plant and antibiotics, the MIC values of the antibiotics had to be determined as these provide the reference point for defining the interactions.

TABLE II

The minimum inhibitory concentrations (MICs) of the extract and the antibiotics used

\begin{tabular}{|c|c|c|c|c|c|c|c|c|c|}
\hline \multirow[t]{2}{*}{ Test isolate } & \multicolumn{9}{|c|}{ Minimum inhibitory concentrations $(\mathrm{mg} / \mathrm{ml})$} \\
\hline & Extract & TET & PEN G & ERY & AMX & CIP & CHL & OXT & AMP \\
\hline S. faecalis ATCC 29212 & 0.5 & 0.016 & 0.4 & 0.256 & 0.412 & 0.004 & 0.128 & 0.008 & 0.004 \\
\hline S. aureus ATCC 6538 & 5.0 & 0.004 & 0.001 & 0.008 & 0.002 & 0.004 & 0.002 & 0.004 & 0.001 \\
\hline B.pumilus ATCC 14884 & 5.0 & 0.001 & 0.001 & 0.002 & 0.001 & 0.002 & 0.004 & 0.002 & 0.001 \\
\hline K. pneumoniae ATCC 10031 & 0.5 & 0.016 & 0.412 & 0.256 & 0.412 & 0.004 & 0.256 & 0.016 & 0.004 \\
\hline P. vulgaris CSIR 0030 & 5.0 & 0.016 & 0.032 & 0.412 & 0.002 & 0.004 & 0.008 & 0.032 & 0.001 \\
\hline$K$. pneumoniae $^{\S}$ & 5.0 & 0.016 & 0.412 & 0.412 & 0.412 & 0.001 & 0.064 & 0.016 & 0.004 \\
\hline B. subtilis ${ }^{\S}$ & 1.0 & 0.001 & 0.001 & 0.001 & 0.001 & 0.001 & 0.002 & 0.004 & 0.001 \\
\hline S. epidermidis $\S$ & 0.5 & 0.016 & 0.412 & 0.412 & 0.412 & 0.001 & 0.064 & 0.016 & 0.004 \\
\hline P. vulgaris ${ }^{\S}$ & 0.5 & 0.032 & 0.004 & 0.412 & 0.001 & 0.001 & 0.008 & 0.064 & 0.004 \\
\hline M. kristinae ${ }^{\S}$ & 0.1 & 0.004 & 0.001 & 0.032 & 0.001 & 0.002 & 0.001 & 0.004 & 0.001 \\
\hline M. luteus ${ }^{\S}$ & 0.5 & 0.004 & 0.001 & 0.004 & 0.008 & 0.002 & 0.001 & 0.004 & 0.002 \\
\hline
\end{tabular}

$\S$ Environmental strain; AMP, ampicilin ; TET, tetracycline; PEN G, penicillin G; ERY, erythromycin; AMX, amoxicillin; CIP, ciprofloxacin; CHL, Chloramphenicol; OXT, Oxytetracycline; EXTRACT, crude methanol extract. 


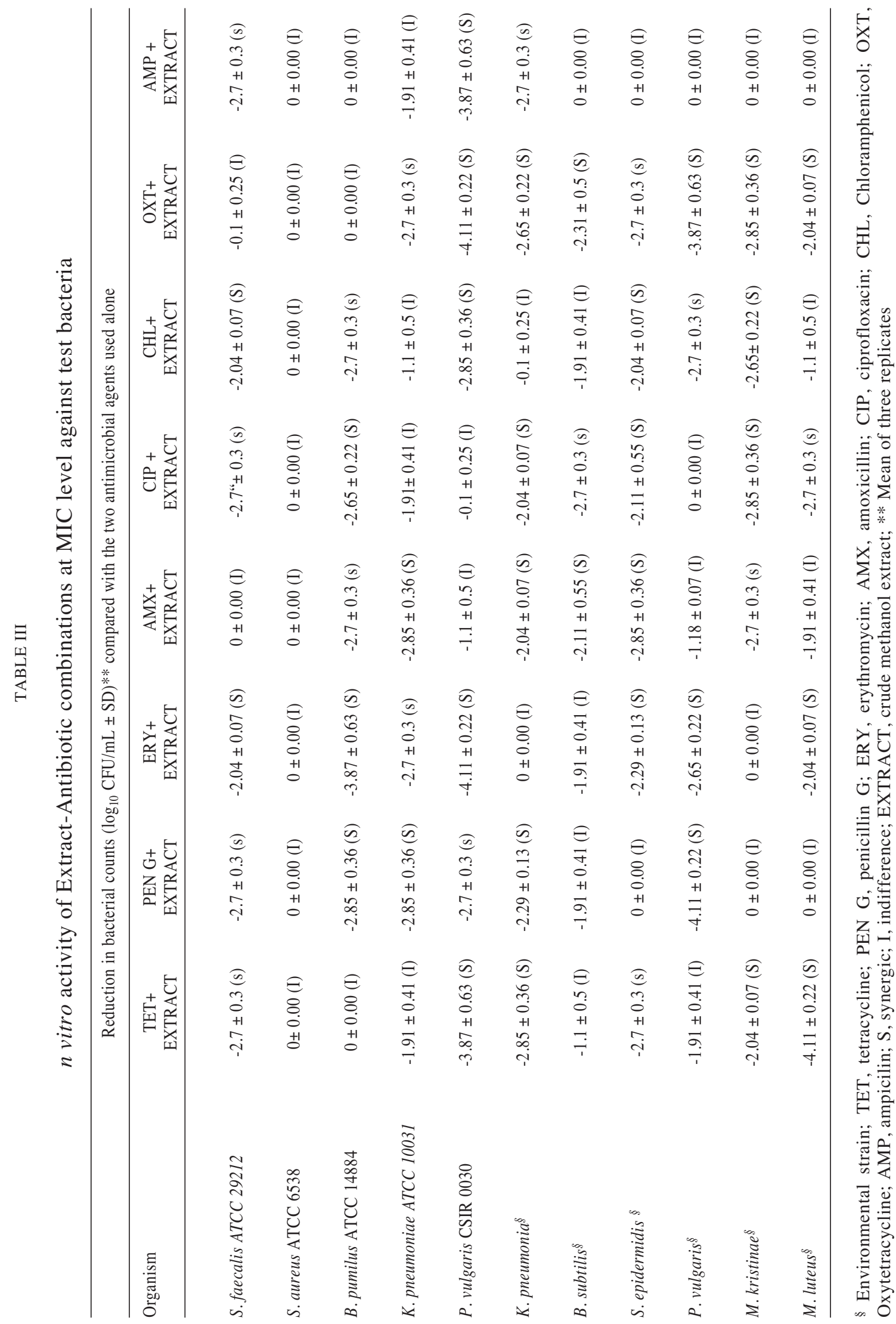




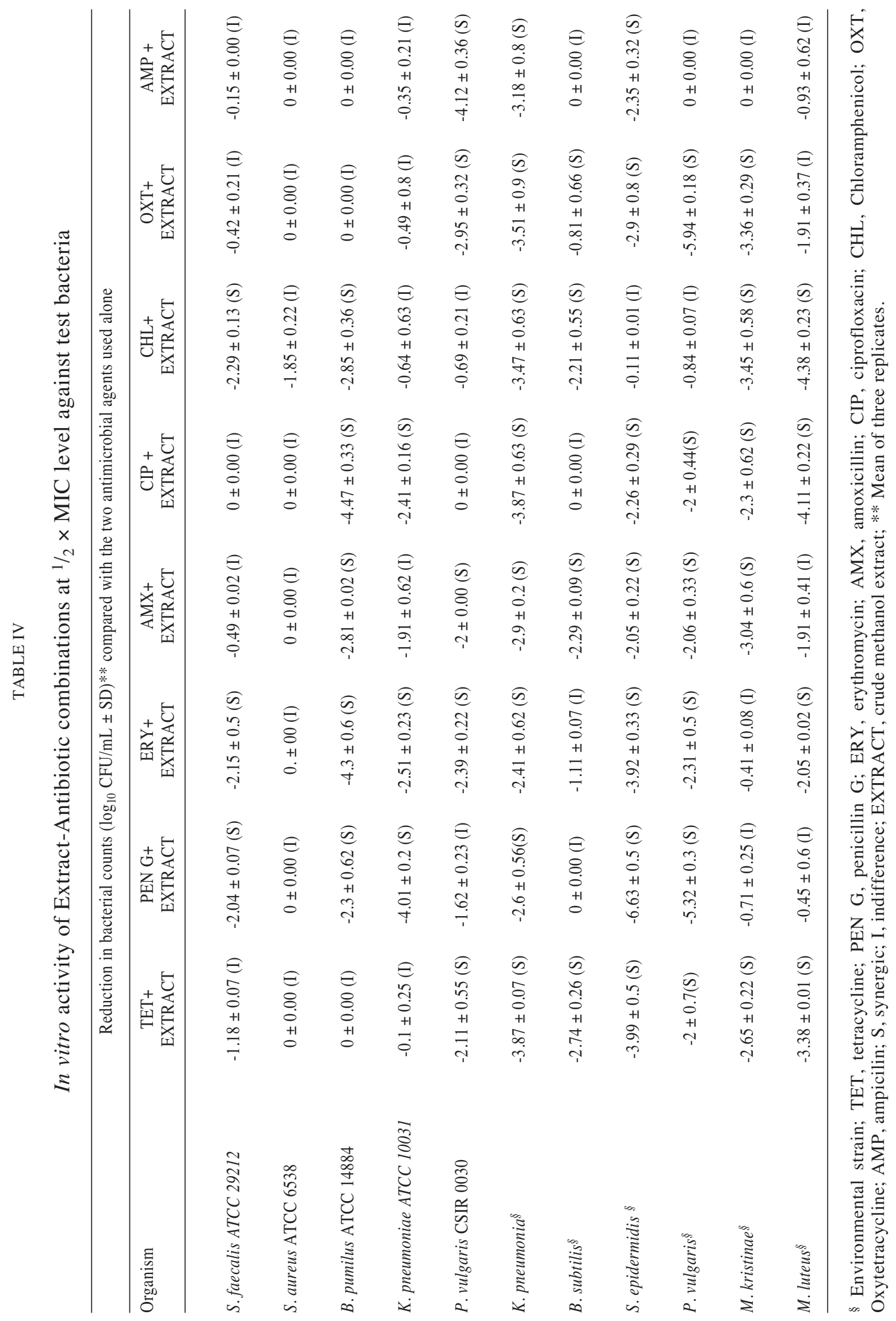


The objective of testing plant extracts for potentials of synergy with antibiotics is to investigate if combinations of such extracts with antibiotics can bring about positive changes in the susceptibility of the test strains, thus necessitating the use of strains resistant to the test antibiotics. Therefore, the British Society for Antimicrobial Chemotherapy (BSAC) and EUCAST, (2000), recommended that MIC breakpoints were used. Although this data is often used in surveillance studies to monitor trends in resistance development, we deemed it convenient to apply in our studies in the absence of a standard. According to the MIC breakpoints, strains of Staphylococcus and Streptococcus with MIC values of $\geq 0.25 \mathrm{mg}$ $1^{-1}$ (for penicillin $\mathrm{G}$ ), $\geq 2 \mathrm{mg}^{-1}$ (for amoxicillin), $\geq 2 \mathrm{mg} \mathrm{l}^{-1}$ (for tetracycline), $\geq 1$ $\mathrm{mg}^{-1}$ (for erythromycin), $\geq 4 \mathrm{mg} \mathrm{l}^{-1}$ (for chloramphenicol) and $\geq 1 \mathrm{mg}^{-1}$ (for ciprofloxacin) are classified as resistant. From results of our MIC values (Table ii), it is obvious that almost all of the bacteria tested were resistant or just slightly susceptible to the test antibiotics (BSAC and EUCAST, 2000). The MIC values for these organisms ranged from 1 to 512 times higher than the predicted breakpoint values. The breakpoint values for enteric bacteria are; 16 $\mathrm{mg} \mathrm{l}^{-1}$ (penicillins), $2 \mathrm{mg} \mathrm{l}^{-1}$ (tetracycline), $16 \mathrm{mg} \mathrm{l}^{-1}$ (chloramphenicol) and $1 \mathrm{mg} \mathrm{l}^{-1}$ (ciprofloxacin) (BSAC and EUCAST, 2000).

In this study, $H$. pedunculatum crude leaf extract inhibited the growth of all the test organisms (Table $\mathrm{i}$ and ii) that have been implicated in wound infections. This finding supports the use of $H$. pedunculatum in the treatment of diseases caused by these pathogens. The antimicrobial activity of $H$. pedunculatum extract successfully inhibited the growth of both Gram-positive and Gram-negative microorganisms used in this study, thus, exhibiting a broad spectrum activities. There are indications that some herbal materials can act as antibiotic resistant inhibitors (Gibbons et al., 2002, Yam et al., 1998). Combinations of some herbal materials and different antibiotics might affect the inhibitory effect of these antibiotics (Sato et al., 2004). Such combinations would be synergistic if there is a decrease in the MIC of each agent of four-fold; partially synergistic if there is a MIC decrease for one drug of four-fold and a decrease of two-fold of the other agent; additive if there is a two-fold reduction in the MIC of both agents; indifference is all interactions not meeting the criteria listed above and not being antagonistic. Antagonistic response refers to where a MIC increase of four-fold for each drug would be observed in combination (Sader et al., 2004).

The time-kill assay detected synergy against both Gram-positive and Gramnegative microorganisms. Strong synergistic interactions with the extract were observed in combinations involving $\beta$ lactam antibiotic (penicillin $\mathrm{G}$ ), as well as protein synthesis inhibitors (tetracycline and erythromycin) against Staphylococcus epidermidis (environmental strain) (Table iii). The synergy detected in this study was not specific to any group of organisms or class of antibiotics. This suggests that crude extracts of this plant could contain a mixture of compounds that can enhance the activity of different antibiotics. Helichrysum species are known to contain a number of antimicrobial compounds (Prinsloo and Meyer, 2006), such as polyphenols and flavonoids. Shibata et al. (2005), in their studies indicated possible exploitation of flavones and their derivatives, including alkylgallate, to intensify the activity of beta lactam antibiotics against methicillin resistant Staphylococcus aureus (MRSA) and methicillin sensitive Staphylococcus aureus (MSSA). Thus natural products and phytocompounds can both be exploited for novel bioactive compounds or may be used in the development of standardized herbal medicine to control infectious diseases.

The antimicrobial and resistance modifying potentials of naturally occurring flavonoids and polyphenolic compounds have been reported in other studies, such as Cushnie and Lamb, (2005) and Sato et al. (2004). This would suggest that the synergy with antibiotics observed in this study could be attributable to such compounds. Some of these compounds, like polyphenols, have been shown to exert their antibacterial 
action through membrane perturbations. This perturbation of the cell membrane coupled with the action of $\beta$-lactams on the transpeptidation of the cell membrane could lead to an enhanced antimicrobial effect of the combination (Esimone et al., 2006). It has also been shown that some plantderived compounds can improve the in vitro activity of some peptidoglycan inhibiting antibiotics by directly attacking the same site (i.e. peptidoglycan) in the cell wall (Zhao et al., 2001).

While the above explanations may account for the synergy between the extracts and $\beta$-lactam antibiotics that act on the cell wall, it might not apply in the case of the observed synergy with other classes of antibiotics with different targets, such as tetracyclines, erythromycin, ciprofloxacin and chloramphenicol. Bacterial efflux pumps are responsible for a significant level of resistance to antibiotics in pathogenic bacteria (Kumar and Schweizer, 2005). Some plant-derived compounds have been observed to enhance the activity of antimicrobial compounds by inhibiting MDR efflux systems in bacteria (Tegos et al., 2002). 5'-methoxyhydnocarpin is an example of an inhibitor of the NorA efflux pump of Staphylococcus aureus isolated from Berberis fremontii (Stermitz et al., 2000). It is likely that the methanolic leaf extract of $H$. pedunculatum could contain potential efflux pump inhibitors. Such compounds are likely to be broad spectrum efflux inhibitors considering that the synergistic effect of the extract was observed on both Gram-positive and Gram-negative organisms, as well as in combination with cell wall inhibiting and protein synthesis inhibiting antibiotics. In fact, some broad spectrum efflux pump inhibitors have been isolated from some plants. Smith et al. (2007) reported one efflux inhibitor (ferruginol) from the cones of Chamaecyparis lawso-niana, which inhibited the activity of the quinolone resistance pump (NorA), the tetracycline resistance pump, (TetK) and the erythromycin resistance pump, (MsrA) in Staphylococcus aureus.

Antibiotics could interfere with bacterial cell wall synthesis, increase bacterial membrane permeability and/or inhibit bacterial protein synthesis at the $30 \mathrm{~S}$ subunit of ribosomes (Matsumura et al., 1999); therefore the different modes of action of the extract from the antibiotics may be an important factor in the enhanced bactericidal efficacy observed when used in combination (Table iii). Since the combinations of extract with antibiotics could inhibit both Gram-positive and Gramnegative pathogenic bacteria, and most combinations were synergistic or indifferent, these kinds of combinations may be practical and beneficial in inhibiting both pathogens. Also, the required dosage of these antibiotics used in combination may be less than when used alone, which may further reduce the occurrence of side effects caused by these antimicrobials.

The strong synergy observed between the crude methanolic extract of the leaves of $H$. pedunculatum and firstline antibiotics is a significant finding demonstrating the therapeutic potentials of this plant. However, the synergy pattern between these plant extracts and antibiotics is suspected to depend mainly on genetic compositions and interactive modes of action, rather than concentrations of the two agents in combinations, although, concentrations relative to MIC may have a major role to play in the outcomes of the combinational experiment. This is supported in our findings from this experiment. For instance, the combination of tetracycline and extract at sub MIC resulted in indifference outcome, whereas, when combined at higher concentration (MIC levels), the outcome was synergistic. On the other hand, that same combination was synergistic at sub MIC and indifference at MIC for Bacillus subtilis and Proteus vulgaris (environmental strains). These kinds of outcomes were observed in all types of extract + antibiotic combinations in this experiment and are irrespective of the Gram's reaction characteristics of the organisms (Table iii). This is similar to what Lee et al., (2006) observed in their experiment when synergy was assayed at both 1/2MIC and MIC levels in Vancomycin Hetero-intermediate Staphylococcus aureus. However, it must be emphasized, that these findings may be difficult to present as a case, 
until after the mechanism of the active component(s) of the crude extract has been studied and determined.

In conclusion, a persistent bacterial infection, particularly in compromised hosts, requires aggressive empiric therapy with at least two antimicrobial agents (Song et al., 2003). Empiric combination antimicrobial therapy is usually applied to expand antibacterial spectrum and reduce the selection of resistant mutants during treatment. In addition, combinations of agents that exhibit synergy or partial synergy could potentially improve the outcome for patients with difficult to treat infections (Song et al., 2003).

Combinational antibiotic therapy to control infections is a viable approach, but will not be effective for a long period of time because of the possible alteration in the susceptibility of bacteria (RochonEdouard et al., 2000). Therefore, the development of new classes of antimicrobial compounds is of significant importance. One possible approach is to determine whether bioactive compounds from natural products and traditional medicinal plants, which have strong bactericidal activity against pathogenic microorganisms, either show synergistic interaction with antibiotics or enhance the susceptibility level of resistant strains to antibiotics.

The methanolic extract from $H$. pedunculatum leaves showed potentials of synergy in combination with some antibiotics against reference strains of pathogenic organisms that often-present problems of drug resistance. The detection of synergy between crude extract of $H$. pedunculatum leaves and antibiotics demonstrates the potential of this plant as a source of antibiotic resistance modifying compounds. It is necessary to carry out a bioassay guided fractionation of the methanol extract of this plant in a bid to isolate and identify the compounds responsible for the synergistic activity with antibiotics. An elucidation of the mechanisms of action of these compounds must be followed by toxicity and in vivo tests to determine the therapeutic applicability of such compounds in combination therapy. These are subjects of on-going investigation in our research group.

\section{ACKNOWLEDGEMENT}

We are grateful to the National Research Foundation (NRF) of South Africa for supporting this research (Grant Ref: TTK2006061400023).

\section{REFERENCES}

AHMAD I, AQIL F (2007). In vitro efficacy of bioactive extracts of 15 medicinal plants against ES_L-producing multidrug-resistant enteric bacteria. Micro Res 162: 264-275

AIYEGORO OA, AFOLAYAN AJ, OKOH AI (2008) In vitro time kill assessment of crude methanol extract of Helichrysum pedunculatum leaves. Afri J Biotech 7: 1684-1688

AL-HEBSHI N, AL-HARONI M, SKAUG N (2006) In vitro antimicrobial and resistance-modifying activities of aqueous crude khat extracts against oral microorganisms. Arch Oral Biol 51: 183-188

AUSTIN DJ, KRISTINSSON KG, ANDERSON RM (1999) The relationship between the volume of antimicrobial consumption in human communities and the frequency of resistance. Proceed Nat Acad Sci 96: $1152-1156$

BASRI DF, FAN SH (2005) The potential of aqueous and acetone extracts of galls of Queercus infectoria as antibacterial agents. Ind J Pharm 37: 26-29

BERINGER PM (1999) New approaches to optimizing antimicrobial therapy in patients with cystic fibrosis. Cur Opinon Pul Med 5: 371-377

BHAT RB, JACOBS TV (1995) Traditional herbal medicine in Transkei. J Ethnopharmacol 48: 7-12

CUSHNIE TPT, LAMB AJ (2005) Antimicrobial activity of flavonoids. Int J Antimicrob Agents 26(5): 343-356

CZINNER E, HAGMASI K, BLAZOVICS A, KERY A, SZOKE E, LEMBERKOVICS E (2000) The in vitro effect of Helichrysum flos on microsomal lipid peroxidation. J Ethnopharmacol 77: 31-35

EDEOGA HO, OKWU DE, MBAEBRE BO (2005) Phytochemical constituent of some Nigerian Medicinal Plants. Afr J Biotechnol 4: 685-688

ESIMONE CO, IROHA IR, IBEZIM EC, OKEH CO, OKPANA EM (2006) In vitro evaluation of the interaction between tea extracts and penicillin G against Staphylococcus aureus. Afr J Biotechnol 5: 1082-1086

EUROPEAN COMMITTTEE FOR ANTIMICROBIAL SUSCEPTIBITY TESTING (EUCAST) 2000 Determination of minimum inhibitory concentrations (MICs) of antibacterial agents by agar dilution. Clin Micro Inf 6: 509-515

GIBBONS S, OHLENDORF SB, JOHNSEN I (2002) The genus Hypericium-a valuable source of antistaphylococcal leads. Fitoterapia 73: 300-304

GRIERSON DS, AFOLAYAN AJ (1999) Antibacterial activity of some indigenous plants used for the treatment of wounds in the Eastern Cape. S Afr J Ethnopharmacol 66: 103-106 
GUILLEMOT D (1999) Antibiotic use in humans and bacterial resistance. Curr Opinion Microbiol 2: 494498

HTTP: //HERBALAFRICA.CO.ZA/HERBSHELICHRY SUM.HTM. [Assessed: 06-05-08]

HUTCHING G (1996) The tale of the white-spotted tussock moth. Forest \& Bird (New Zealand) pp14-19

IROBI ON, YOUNG M, ANDERSON WA (1996) Antimicrobial activity of Annato (Bixaorella) extract. Int J Pharmacog 34: 87-90

IWU M (1993) Handbook of African medicinal plants. CRC Press, Boca Raton, FL

KUMAR A, SCHWEIZER HP (2005) Bacterial resistance to antibiotics: Active efflux and Reduced uptake. Adv Drug Deliv Rev 57: 1486- 1513

LEE JY, OH WS, KO KS, HEO ST, MOON CS, KI HK, KIEM S, PECK KR, SONG JH (2006) Synergy of arbekacin-based combinations against vancomycin hetero-intermediate Staphylococcus aureus. J Korean Med Sci 21: 188-192

LEVY SB (2002) The Antibiotic Paradox: How Misuse of Antibiotics Destroys Their Curative Powers (2nd ed.), Perseus Books, Boston

MARQUEZ B, NEUVILLE L, MOREAU NJ, GENET JP, SANTOS AF, ANDRADE MCC, SANT' ANA AEG (2005) Multidrug resistance reversal agent from Jatropha elliptica. Phytochem 66: 1804-1811

MATHEKGA ADM, MEYER JJM, HORN MM, DREWES SE (2000) An acylated Phloroglucinol with antimicrobial properties from Helichrysum caespititium. Phytochem 53: 93-96

MATSUMURA N, MINAMI S, WATANABE Y, IYOBE S, MITSUHASHI S (1999) Roles of permeability in the activites of beta-lactams against gram-negative bacteria which produce a group 3 beta-lactamase. Antimicrob Agents Chemother 43: 2084-2086

MEYER JJM, DILIKA F (1996) Antibacterial activity of Helichrysum pedunculatum used in circumcision rites. J Ethnopharmacol 53: 51-54

MURRAY M (1995) The healing power of herbs. Prima Publishing. Rocklin, CA; 162-171.

NEUGEBAUER KA, GILLILAND SE (2005) Antagonistic action of Lactobacillus delbrueckii ssp. lactis RM2-5 toward spoilage Organisms in cottage cheese. J Dairy Sci 88: 1335-1341

OKWU DE (1999) Flavouring properties of spices on Cassava Fufu. Afr J Rts Tuber Crp 3(2): 19-21

OKWU DE (2001) Evaluation of the chemical composition of indigenous Spices and Flavouring Agents. Global J Appl Sc 7(3): 455-459

PANKEY G, ASHCRAFT D, PATEL N (2005) In vitro Synergy of Daptomycin plus Rifampin against Enterococcus faecium Resistant to both Linezolid and Vancomycin. Antimicrob Agents Chemother 49(12): 5166-5168

PRINSLOO G, MEYER JJM (2006) In vitro production of phytoalexins by Helichrysum kraussii. S Afr J Bot 72: 482- 483

ROBBERS J, SPEEDIE M, TYLER V (1996) Pharmacognosy and Pharmacobiotechnology. Williams and Wilkins, Baltimore; 1-14

ROCHON-EDOUARD S, PESTEL-CARON M, LEMELAND JF, CARON F (2000) In vitro synergistic effect of double and triple combinations of $\beta$-lactams, vancomycin and netilmycin against methicillin resistant Staphylococcus aureus strains. Antimicrob Agent Chemother 44: 3055-3060

SADER HS, STREIT JM, FRITSCHE TR, et al. (2004) Antimicrobial activity of Daptomycin against multidrug-resistant gram-positive strains collected worldwide. Diagn Microbiol Infect Dis, 50: 201-204

SATO M, TANAKA H, YAMAGUCHI R, KATO K, ETOH H (2004) Synergistic effects of mupirocin and an isoflavanone isolated from Erythrina variegata on growth and recovery of methicillin-resistant Staphylococcus aureus. Int J Antimicrob Agents 24: 43-48

SHIBATA H, KONDO K, KATSUYAMA R, KAWAZOE $\mathrm{K}$, SATO Y, MURAKAMI K, TAKAISHI Y, ARAKAKI N, HIGUTI T (2005) Alkyl Gallates, Intensifiers of $\beta$-Lactam Susceptibility in MethicillinResistant Staphylococcus aureus. Antimicrob Agents Chemother 49: 549-555

SIBANDA T, OKOH AI (2008). In vitro evaluation of the interactions between acetone extracts of Garcinia kola seeds and some antibiotics. Afr J Biotech 7: 1672-1678

SMITH ECJ, WILLIAMSON EM, WAREHAM N, KAATZ GW, GIBBONS S (2007) Antibacterials and modulators of bacterial resistance from the immature cones of Chamaecyparis lawsoniana. Phytochem 68: 210-217

SONG W, WOO HJ, KIM JS, LEE KM (2003) In vitro activity of $\beta$-lactams in combination with other antimicrobial agents against resistant strains of Pseudomonas aeruginosa. Int J Antimicrob Agents 21: 8-12

STAPLETON PD, SHAH S, ANDERSON JC, HARA Y, HAMILTON-MILLER JMT, TAYLOR PW (2004) Modulation of $\beta$-lactam resistance in Staphylococcus aureus by catechins and gallates. Int J Antimic Agents 23: $462-467$

STERMITZ FR, LORENZ P, TAWARA JN, ZENEWICZ LA, LEWIS K (2000) Synergy in a medicinal plant: Antimicrobial action of berberine potentiated by 5 'methoxyhydnocarpin, a multidrug pump inhibitor. Appl Biol Sci 97: 1433-1437

STUART B LEVY, BONNIE MARSHALL (2005) Antibacterial resistance worldwide: causes, challenges and responses. Nat Med 10: 122-129

TEGOS G, STERMITZ FR, LOMOVSKAYA O, LEWIS K (2002) Multidrug Pump Inhibitors Uncover Remarkable Activity of Plant Antimicrobials, Antimicrob Agents Chemother 46: 3133-3141

WHITE RL, BURGESS DS, MANDURU M, BOSSO JA (1996) Comparison of Three Different In Vitro Methods of Detecting Synergy: Time-Kill, Checkerboard, and E test. Antimicrob Agents Chemother 40: 1914-1918

YAM TS, HAMILTON-MILLER JMT, SHAH S (1998) The effect of a component of tea (Camelia sinensis) on methicillin resistance, PBP2' synthesis, and $\square \leq-$ lactamase production in Saureus. J Antimicrob Chemother 42: 211-216

ZHAO WH, HU ZQ, OKUBO S, HARA Y, SHIMAMURA $T$ (2001) Mechanism of synergy between Epigallochatechin gallate and $\beta$-Lactams against methicillin resistant Staphylococcus aureus. Antimicrob Agents Chemother 45: 1737-1742 